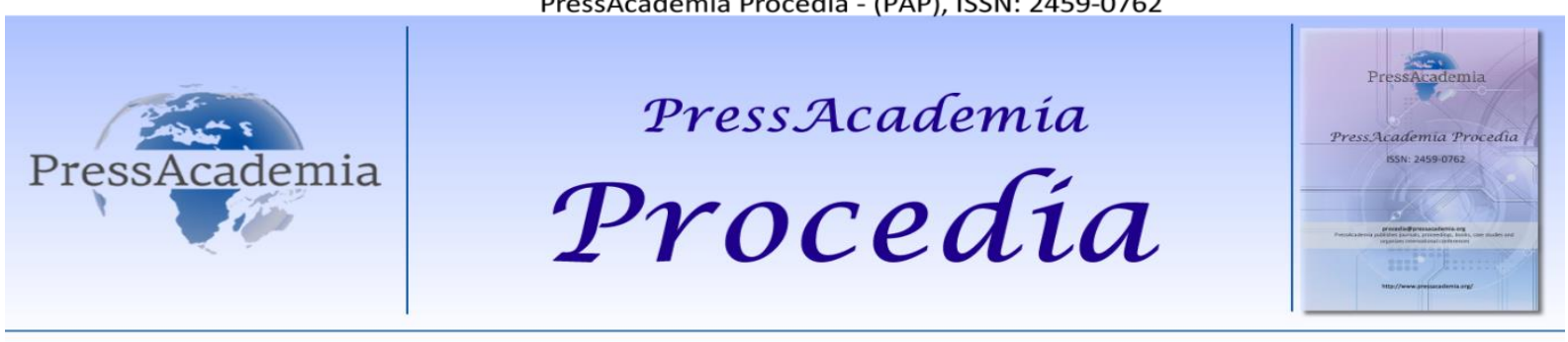

Global Business Research Congress (GBRC), May 24-25, 2017, Istanbul, Turkey

\title{
STOCK CONTROL AND MANAGEMENT IN FURNITURE INDUSTRY: A CASE STUDY
}

\section{DOI: 10.17261/Pressacademia.2017.658 \\ PAP- GBRC-V.3-2017(84)-p.783-789}

\author{
Mehmet Colak ${ }^{1}$, Haydar Gol ${ }^{2}$, Tahsin Cetin ${ }^{3}$ \\ ${ }^{1}$ Muğla Sıtkı Koçman University, Technology Faculty, Wood Working Industrial Engineering, Muğla, Turkey. cmehmet@mu.edu.tr \\ ${ }^{2}$ Muğla Sıtkı Koçman University, Technology Faculty, Wood Working Industrial Engineering, Muğla, Turkey. haydargol@posta.mu.edu.tr \\ ${ }^{3}$ Muğla Sıtkı Koçman University, Technology Faculty, Wood Working Industrial Engineering, Muğla, Turkey. tahsincetin@mu.edu.tr
}

To cite this document

Colak, M., H. Gol and T. Cetin, (2017). Stock control and management in furniture industry: a case study, PressAcademia Procedia (PAP), V.3, p.783-789.

Permemant link to this document: $\underline{\text { http://doi.org/10.17261/Pressacademia.2017.658 }}$

Copyright: Published by PressAcademia and limited licenced re-use rights only.

\begin{abstract}
Economic growth and development of the countries are measured with the income increase to be achieved at the end of the production. Even though there are some criteria presenting the development levels of the countries, the significant differences among the development levels of the countries stem from the success in the production process. The concept of production is important for both countries and enterprises. Enterprises have numerous limitations in their activities related to the production. These limitations may include internal factors such as price, quality and time that are associated with the quality of the product and can be controlled by the enterprise as well as external factors such as uncertainties in the market and customer demands that are beyond the control of the enterprise. In this respect, the aim of the study is to present alternative models for stocks of the enterprises in the furniture industry through current package programs by addressing the basic functions of the enterprise management and the process of taking the optimum decisions through the effective use of the available resources under predictable and unpredictable constraints. In the present study, it was determined that enterprise control and stock control and management system are needed in order to make the production in the most effective manner, fulfil the orders, prevent interruption in the production activities, achieve a balance between the suppliers and consumers, increase efficiency, keep stocks at the optimal level and minimise the costs related to the stocks.
\end{abstract}

Keywords: Furniture sector, stock management, ERP, stock costs, Dynamics AX.

JEL Codes: M00, M11, M10

\section{MOBILYA ENDÜSTRISINDE STOK KONTROLÜ VE YÖNETIMI: BIRR UYGULAMA}

\section{ÖZET}

Ülkelerin ekonomik anlamda büyümesi ve kalkınması, üretim sonucu sağlanacak gelir artışı ile ölçülmektedir. Ülkeler arasında gelişmişlik düzeyini ortaya koyan bir dizi ölçüt olsa da, gelişmişlik düzeyleri arasındaki anlamlı farklılaşmanın arkasında üretim sürecinde başarılı olma yatmaktadır. Üretim kavramı, salt ülkeler için değil, aynı zamanda işletmeler için de önemli kavramlardan biridir. İşletmeler üretime ilişkin faaliyetlerinde, pek çok kısıt altında bulunmaktadır. Bu kısıtlar içinde fiyat, kalite veya zaman gibi ürünün niteliğinden kaynaklanan ve işletmenin kontrolü altındaki faktörler olabileceği gibi, piyasa ve müşteri talebindeki belirsizlikler gibi işletmenin kontrolü dışında gerçekleşen dışsal faktörler de olabilir. Bu amaçla çalışma kapsamında, öngörülebilen veya öngörülemeyen kısıtlar altında, mevcut kaynakları etkin bir biçimde kullanarak en uygun (optimum) kararların alınması sürecini, işletme yönetiminin temel işlevlerini güncel paket programlar ile mobilya sektöründeki işletmelere yönelik stok konusunda alternatif modeller ortaya koymaktır. Yapılan çalışmayla üretimin en etkili şekilde gerçekleştirilip, siparişlerin karşılanması ve üretim faaliyetlerinin kesintiye uğramaması için tedarikçiler ve tüketiciler arasında dengenin kurulabilmesi ile verimliliğin artmasını sağlamak, optimal düzeyde stok bulundurmak ve stoklara yapılan maliyeti en aza indirmek için işletme kontrolüne ve stok kontrolü yönetim sistemine gereksinim olduğu belirlenmiştir.

Anahtar Kelimeler: Mobilya sektörü, stok yönetimi, ERP, stok maliyeti, Dynamics AX.

JEL Kodları: M00, M11, M10 


\section{GíRiş}

İşletme yönetimi, işletme içerisinde farklı birimlerin eşzamanlı olarak organizasyon ve kontrolü ile de ilgilenmek durumundadır. Bu bağlamda, üretim planlama ve kontrolü, kalite kontrolü, stok kontrolü gibi fonksiyonlar, üretim yönetimiyle doğrudan alakalı olduğu gibi işletme yönetiminin de temel fonksiyonları arasında yer almaktadır. Bunlar içinde stok kontrolü fonksiyonu son yıllarda oldukça önem kazanmış olup, bu alanda pek çok değişim ve gelişme yaşanmıştır. Buna bağlı olarak, stoklarla ilgili temel ilke ve stratejilerin belirlenmesinde yetersiz kalan stok kontrolü kavramı yerine stok yönetimi kavramı kullanılır olmuştur. Stok yönetimi; işletmelerin, üretim, satış ve finans durumlarını göz önüne alarak, işletmenin yapısına uygun en ekonomik stok miktarını belirlemeyi ve stokların bu seviyede tutulmasını amaçlar. Bu nedenle stok yönetiminde stok düzeyleri ve stok hareketleri sürekli olarak kontrol edilmelidir. İşletmeler açısından stok yönetiminin önemi, maliyetlerin azaltılarak kârın en maksimize edilmesi temelinden ileri gelmektedir. Çünkü işletme için stok bulundurmanın veya bulundurmamanın maliyetleri vardır. Bu bağlamda stok yönetimi, stoklara yapılacak en uygun yatırım kararlarının alınması amacına hizmet etmektedir.

\section{LITERATÜR INCELEMESI}

Bir sanayi işletmesinde üretimden sorumlu olanların amacı, imalat programının aksaksız olarak gerçekleştirilmesidir. Buna göre malzeme eksikliğinden üretimin aksaması gibi bir sorunu ortadan kaldırmak için üreticiler her malzemeden olabildiğince fazla elde bulundurulmasını isterler. İşletmede finansman bölümünün amacı ise işletmenin faaliyetlerini en az sermaye bağlayarak gerçekleştirmektir. Bundandır ki finansman bölümü çalışanları stokların gereksinimi karşılayabilecek en düşük düzeyde tutulmasını isterler. Bu iki zıt görüşü birleştirmek amacı ile işletmecilikte "Stok Kontrolü ve Yönetimi" son yıllarda büyük önem kazanmış ve bu alanda matematiksel yöntemler ve bilgisayardan geniş çapta yararlanılmıştır (Güneçıkan, 2008). Üretimin ilk basamağını oluşturan hammadde girişinden başlayarak son mamulün oluşmasına kadar üretime katılan veya duran yarı mamul ve mamul maddenin tüm stok hareketlerinin takip edilmesi ve bunların her kademede üretim faaliyetlerinin aksamayacağı kadar çok, ama gereğinden fazla olmasını engellemek amacıyla yapılan çalışmalara "stok kontrolü" denmektedir (Korkmaz, 2001). Stok kontrolünün temel amacı stok yönetimi yapabilmek için gerekli olan stok düzeyinin tespiti ve sipariş zamanlarının belirlenmesidir. Stok kontrolü sayesinde toplam stok maliyetlerini minimize edebilecek bir stok düzeyine erişme olanağı elde edilmektedir. Bu nedenle her işletme; büyüklüğüne, yönetim politikalarına, üretim tipine, mali olanaklarına, ülkenin ekonomik politikasına, üretilen mal ve hizmetin türüne göre oluşturduğu bir stok kontrol sistemi uygular (Erk, 2009).

İyi bir kontrol örgüt etkinliğinin hem sonucu hem de başlangıcıdır. Bu nedenle üretim olanaklarının optimum değerini saptayabilen, işletmenin iç piyasa değerini arttıran, ihracat gücü yaratan bir kontrol anlayışını benimsemesi, yaşamsal amaçları doğrultusunda gerekli ve zorunlu bir adımdır.

- Çağdaş örgüt anlayışındaki kontrol işlevi tüm birimlerin aksayan yönlerini saptamak,

- İşletme bünyesindeki aksaklıkları işletme politikaları doğrultusunda değiştirme yönünde örgüt kademelerini bilgilendirmek,

- İşletme etkinliği ve ulusal ekonominin gerekleri doğrultusunda bir yörüngeye oturtmak için gerekli birimleri harekete geçirmek,

- Plan ve programları yeni baştan gözden geçirmek, aksayan uygulamaları plandan çıkartmak, yeni belirlenen yöntemleri plan dahiline sokmak zorundadır.

Bu nedenle işlevsel aksaklıkların önce işletmenin temel amaçlarını zedelediği, sektörel zaafların oluşmasını kaçınılmaz kıldığı ve ülke genelinde üretim olanaklarını geriletici etki yaptığını söyleyebiliriz. Kontrol 'işletmede kontroller arasında en iyi iç ilişkiye ve toplam iç kontrol yapısı içerisinde en iyi bileşene nasıl ulaşılabilir' konusunda yönetime yardımcı olur (Yılancı, 2003). Günümüzde üretim sistemlerinde stoklar her kademeden yöneticinin yakından ilgilenmesi gereken bir sorun haline gelmiştir. Yanlış stok politikaları veya uygulama hataları yüzünden azımsanamayacak sayıda işletme kritik duruma düşmüştür. Verimli ve etkin bir stok sisteminde özellikle üretim planlama, kontrol ve satışın rolü vardır. Genel olarak stok kontrol; stok miktar ve çeşitlerinin işletmelerin tedarik, üretim ve mali imkanlarına göre en rasyonel ve ekonomik bir şekilde belirlenmesi yöntemidir. Kısaca stok kontrolünde temel amaç malzemenin ne eksik ne fazla fakat yeterli miktarlarda işletmede hazır bulundurularak üretimin aksatılmadan yürütülmesidir. Bir başka deyişle:

- İstenilen zamanda • İstenilen miktarda • İstenilen yerde • İstenilen kalitede;

malzemenin sağlanabilmesi için ne zaman, ne kadar tedarik edilebileceği sorularına cevap bulma işlemidir. Üretim sistemi büyüdükçe, mamul çeşidi arttıkça, tedarik, talep ve imalata ilişkin faktörlerdeki belirsizlik ve aralarındaki ilişkilerin karmaşıklığı, stok bulundurmayı zorunlu kılar. Stok kontrolü, malzemelerin ve ürünlerin gerektiği zaman yeterli miktarda sağlanmasını güvence altına almalı ve aşırı stok maliyetlerine engel olmalıdır. Stok kontrolünün başlıca amaçları şunlardır (Güneçıkan, 2008): 
- Stok yatırımını ve depolama giderlerini minimize etmek, üretimin hammaddesiz ve yarı mamulsüz kalmasını engelleyecek miktarda stok bulundurmak, etkin bir stok kayıt sistemi kurmak, muhasebeye, stok konusunda doğru ve yeterli bilgi vermek, ekonomik sipariş için, satın alma bölümü ile işbirliği yapmak.

İşletmeleri stok bulundurmaya zorlayan faktörleri ortaya koyabilmek için, hangi nedenlerle stok bulundurduklarını; söz konusu faktörleri derli toplu bir şekilde ifade eden K. J. Arrow, bireylerin para bulundurma nedenleri ile işletmelerin stok bulundurma nedenleri arasında bir ilişki kurmuş ve işletmelerin stok bulundurma nedenlerini, bireylerin para bulundurma nedenleri altında toplamıştır. Buna göre, işletmeler de bireyler gibi işlem, temkin ve spekülasyon nedenleri ile stok bulundururlar (Kaya, 2006). Bir işletmenin stok bulundurmasının birçok nedeni vardır. Ancak ana neden malların tam talep edildiği zaman sağlanmasının fiziksel olarak mümkün olmamasıdır. Başka bir deyişle, arz ve talep süreçlerinin farklı hızlarda olmaları stokların oluşmasına veya onlara ihtiyaç duyulmasına neden olur. Stok bulundurmayı zorunlu kılan sebepler ve bu işten beklenen yararlar şöyle sıralanabilir (Yeşiltaş, 2007);

1- Bir mamulün üretilmesi ve dağıtımının yapılabilmesi için gerekli işlemleri bağımsız yapmak,

2- Üretim olanağı yetersiz kaldığında veya talepte ani artışlar olduğunda tüketici talebini karşılamak,

3- Üretim seviyesini korumak ve işgücünün kalıcılığını sağlamak,

4- Talepteki dalgalanmaların etkisine karşı bir tampon oluşturmak,

5- Miktar iskontolarından yararlanmak,

6- Fiyat spekülasyonu veya yokluk tehlikesine karşı önlem.

Rekabet şartları güçleşen ve kâr marjları azalan işletmeler, faaliyetlerini sürdürebilmek için stokları üzerinde artık daha titiz bir kontrol sistemi kurmuşlardır. İşletmeler, ucuz satış gibi tedbirlerle fazla stoklarını nakde çevirdiklerinde zarara uğradıklarından, stoklarını daha önceden kontrol etmeye başlamışlardır. Böyle bir sistemin işletme ekonomisi açısından sağlayacağı yararlar aşağıdaki şekilde sıralanabilir (Bilgin, 2013);

1. Üretim faaliyetlerinin düzgün biçimde yürütülmesine yardımcı olur. İş istasyonlarında yığılmalar azalır,

2. Stoklara bağlanan parça ihtiyaca göre saptandığından iyi bir finans yönetimine imkân sağlar,

3. Tedarik ve satış masrafları azalır,

4. Üretim programlarının kolay ve gerçeğe uygun düzenlenmesi mümkün olur,

5. Etkili bir maliyet muhasebesi sisteminin ihtiyacı olan bilgilerin pek çoğu kolay ve duyarlı biçimde toplanabilir,

6. Dikkatsizlik yüzünden ziyan olan malzeme ve mamullerin miktarı azaltılır.

Bir işletmede var olan veya olması gereken stoklarla ilgili maliyetlere stok maliyetleri denilmektedir. Stoka sahip olmak başlı başına bir maliyet unsuru iken, stok bulundurmanın ve bulundurmamanın da bazı maliyetleri vardır. Her stok kontrol probleminde amaç bu maliyetler arasındaki denge noktasının bulunmasıdır. Çünkü bu maliyet kalemlerinin bir kısmı stok miktarı arttıkça artmakta, bir kısmı stok miktarı arttıkça azalmakta, bir kısmı ise stok miktarından bağımsız olarak sabit kalmaktadır. Stok miktarı arttıkça artan maliyet kalemleri arasında sermayenin fırsat maliyeti, depolama maliyeti, vergi ve sigorta, kalite maliyetleri, koordinasyon maliyetleri, yıpranma, eskime ve modası geçme maliyetleri sayılabilir. Stok miktarı arttıkça azalan maliyet kalemlerine örnek olarak sipariş maliyeti, üretime hazırlık (kurulum) maliyeti, satın alma maliyeti, üretim maliyeti ve müşterinin kaçırılması maliyeti verilebilir. Bazı maliyet kalemleri ise stok miktarından bağımsızdır (Çolak, 2008).

Fiziksel stoklama maliyeti ile fırsat maliyeti toplamından oluşan elde bulundurma maliyetleri, stoklara yapılan yatırımların parasal değeri ile depolama, eskime riski, hizmet maliyetlerini kapsamaktadır. İşletme içinde oluşan bu maliyetler, süre ve hacme göre artan stoklama maliyetleridir.

Bu maliyet türlerini şu şekilde açıklayabiliriz (Öztürk, 2005):

- Depolanma alanı maliyetleri: deponun, kira (depo işletmeye ait değilse), aşınma, emlak vergisi (depo işletmeye aitse), bina sigortası, güvenlik, ışıklandırma, ısı ve nem kontrolü, ısıtma veya soğutma vb. maliyetleri ile ithal edilen malların gümrükte depolanma maliyetlerinden oluşmaktadır (bu maliyet depolama süresi ve malların hacmi ile doğru orantılıdır).

- Hizmet (servis) maliyetleri: stok için ödenen vergi, sigorta, taşıma ve sayım giderleridir. Sigorta giderleri, stok düzeyinin değişimi ile değişir. Eldeki stok miktarına göre yılda bir kez ödenen vergi, stok miktarına bağııdır. Taşıma ve sayım maliyetleri ise stok miktarı ile orantılı olarak değişir. 
- Risk maliyetleri: genellikle tahmin yapılarak belirlenen ve stoktaki malların bozulma, çalınma, teknolojik eskime, kaybolma vb. durumlarından kaynaklanan bu maliyetlerin stok düzeyi ile orantılı olarak değişim gösterdikleri varsayılır. Kısaca, herhangi bir süre içinde işletmeye bağlanan stokların parasal değeri ile bu mallara yapılan her türlü masraf olarak tanımlanabilen elde bulundurma maliyeti, o süre içindeki stok yatırımı ile orantılıdır (Bayar, 2004).

Üretim faaliyetlerinin düzenli yürütülmesi ve işgücü, makine, malzeme kaynaklarının etkin kullanımını sağlar. Malzeme ve parça yokluğu nedeniyle beklemeleri en aza indirir. Makineler arası malzeme yığılmalarını ortadan kaldırır, üretim planlamalarının daha kolay ve gerçeğe uygun yapılmasını sağlar. Stoklar, rasyonel esaslara göre faaliyet gösteren ve iktisadî düzende işlevini gerektiği gibi yerine getirmek isteyen işletmeler için kaçınılmaz bir unsurdur. Stok bulundurmadan faaliyetlerini yürüten işletme pek istisnaidir (Kaya, 2006).

Stok bulundurmayı-bulundurmamayı zorunlu kılan sebep ve nedenler ile bu işten beklenen yararlar Yeşiltaş, 2007'ye göre aşağıdaki gibi:

- Bir mamulün üretilmesi ve dağıtımının yapılabilmesi için gerekli işlemleri birbirlerinden ayırarak, bağımsız kılmak,

- Üretim olanakları yetersiz kaldığında veya talepte mevsimlik patlamalar olduğunda tüketici talebini karşılamak,

- Üretim seviyesini korumak ve işgücünün kalıcılığını sağlamak,

- Talepteki dalgalanmaların etkisine karşı bir tampon oluşturmak,

- Miktar iskontolarından yararlanmak,

- Fiyat spekülasyonu veya yokluk tehlikesine karşı önlem,

• Üretimin ekonomik olarak sürdürülebilmesi için olası üretim artışlarını göz önüne almaktır.

Stok bulundurmama nedenleri olarak ta;

- Elde bulundurma maliyetleri

- Müşteri isteklerinin maliyeti

- Üretim koordinasyonunun maliyeti

- Büyük parti kalite maliyeti

- Üretimde oluşabilecek problemlerin maliyeti

- Yatırımlardaki azaltılmış gelirlerin maliyeti

İşletmenin elinde stok bulundurmasının yararları kadar sakıncaları da vardır. Sakınca olarak şunlar sayılabilir:

- Stokların fazla yer kaplama durumu ve yüksek depo kirası,

- Gereğinden çok depo personeli çalıştırma durumu,

- Stokların bozulma, değer kaybetme, aşınma ve eskime durumları,

- Sigorta değerlerinin yüksek olması durumu.

İşletmede başarının önemli bir unsurunu oluşturan stok kontrolünün faydaları şöyle sıralanabilir:

- İhtiyaç duyulan minimum stok seviyesi ile çalışıldığından, stoklara bağlanan paranın da ihtiyaç sınırları içinde tutulması sağlanmış olur, böylece finansman sorunu sağlıklı bir yapıya sahip olur.

- Stok bulundurma maliyetinde ve diğer maliyetlerde azalmaya neden olur olur,

- Ürün ve malzeme alım-satım masraflarında azalma sağlanmış olur,

- Üretim planlamasına yardımcı olur. Yani makine, insan ve malzeme arasında iyi bir koordinasyon sağlanmasına yardımcı olur, böylece üretimde yığılma veya boş durmalar azalarak üretimdeki aksamalar önlenmiş olur,

- Maliyet muhasebesi için ihtiyaç duyulan her türlü bilginin sağlıklı bir şekilde elde edilmesi sağlanmış olur,

- Üretim akışı kontrol altına alınarak müşterilere daha iyi hizmet sağlar,

- Çeşitli nedenlerden dolayı kullanılamayacak duruma gelen malzeme ve mamul kayıpları önler,

- Aşırı stoklar ortadan kalkar, böylece en düşük stok yatırımı ile üretim gereksinimleri karşılanır, 
- Müşteri talebini karşılayacak yüksek stok ile sermaye yatırımını minimum düzeyde tutacak stok arasındaki dengenin bulunması, stok kontrolünün en zor kısmını oluşturmaktadır (Öztürk, 2005).

\section{VERI, YÖNTEM VE BULGULAR}

\section{Uygulama Yapılan Firma}

Otomotiv, iletişim, petrol, finans, kozmetik, saat, elektronik, ağırlama ve hizmet gibi farklı endüstriden çok önemli müşterilerle çalışabilen ayrı bir işletmedir. İşletmenin bir katı görsel iletişim ürünleri, diğer katı da kurumsal mobilya üretimine ayrılmış, son teknoloji ile donatılmış $50.000 \mathrm{~m}^{2}$ üretim tesisine sahip en son teknikler ve en yeni teknoloji ve kontrol sistemlerini kullanarak, müşterileri için en kaliteli ürünleri üretmektedir. Metal, ahşap, akrilik ve vinil gibi ana hammaddelerin işlenmesinin yanında, ışıklandırma ve dijital baskı gibi servisleri de tek çatı altında müşterilerinin hizmetine sunmaktadır. Ayrıca hammadde ve bitmiş ürünler için $10.000 \mathrm{~m}^{2}$ depolama alanına sahiptir. İmalat süreçleri Ahşap, Metal, Akrilik, Katı Akrilik, Vinil, Dijital Baskı, Işıklandırma ve Döşeme gibi ana başlıklar altında toplanabilir.

Bu kısımda firmanın kullanmakta olduğu program olan, Microsoft Dynamics AX ‘ t tanıtılmıştır.

\section{Microsoft Dynamics AX}

Axapta veya Microsoft Dynamics AX, Microsoft tarafından üretilen, yazılımı ve 1998 yılından beri kullanılan kurumsal kaynak planlaması (ERP) alanında en çok tercih edilen programlardan birisidir. 2002 yılında adı Navision Axapta olarak anılmaya başlanmış, 2003 yııında ise Microsoft tarafından satın alınıp Microsoft Dynamics Ax adını almıştır (Anonim 1, 2016).

Axapta, Navision'un 2003 yılında Microsoft tarafından satın alınması ile Microsoft Business Solutions ürün ailesine dahil olan yazılım günümüzde 45 dili desteklemekte ve alanında yaygın olarak kullanılmaktadır. Microsoft Business Solutions ürün grubu 2006 yılında Microsoft Dynamics olarak isim değiştirmiş̧ir. Axapta'nın ismi bu andan itibaren Dynamics AX olmuştur. Dynamics Ax'ın temel özelliği açık kaynak kodlu bir ERP olmasıdır.

Microsoft Dynamics AX, Microsoft'un bulut ERP hizmetidir ve Microsoft Azure için özel olarak geliştirilmiştir. Kuruluşların özel gereksinimlerini destekleyici bir hizmet verirken altyapı yönetimi zorluklarını ortadan kaldırarak sürekli olarak değişen iş ortamlarına uyum sağlar. Microsoft Dynamics AX, bir dizi ERP, BI, altyapı, bilgi işlem ve veritabanı hizmetlerini tek bir teklifte bir araya getirerek, kuruluşların iş ortaklarından gelen özel çözümlerle genişletilebilir sektöre özgü ve operasyonel işletme süreçleri yürütmelerine olanak sağlar. Kuruluşlar, "kullandıkça öde" modeliyle kolaylıkla iş süreçleri ve kullanıcı ekleyerek işletmelerinin büyüme hızına ayak uydurabilirler. İşleri hızlandırmak üzere tasarlanan Microsoft Dynamics AX, akıllı kullanıcı arayüzü sayesinde kullanıcıların hızla akıllı kararlar vermesine yardımcı olur, kanıtlanmış yöntemler ve uygulamalarla iş süreçlerini daha hızlı dönüştürürken, kuruluşların bulut seçeneği ve esnekliğiyle her zaman ve her yerden iş yapmalarına olanak sağlar (Anonim 2, 2016). Dynamics Ax'ın temel özelliği açık kaynak kodlu bir ERP olmasıdır (Anonim 3, 2016).

Malzeme ve Stok Kontrolü Yapılan Firmanın Uygulaması Basamakları;

1. İşlem proje yönetimi; satış siparişlerini, alacak hesapları modülünden müşteri ayrıntıları sekmesinde müşteri bilgilerini seçerek Axapta sistemine aktarır.

2. İşlem proje yönetimi; satış siparişini açtıktan sonra, sistem; satış siparişi ayrıntıları sekmesinden satış sipariş takip numarası verir.

3. İşlem proje yönetimi açtığı siparişine talep ettiği mamul ürün kodlarını ekler ve eklediği mamul ürünlerin renk, konfigürasyon, ambar ve adet detaylarını belirleyerek fiyatlı şekilde siparişi netleştirir.

4. İ̧̧lem proje yönetimi satış sipariş formu oluşturur ve oluşturulan satış sipariş formu planlama departmanına gönderilir.

5. İ̧̧lem planlama departmanı gelen sipariş formunu inceledikten sonra onay verir. Sipariş türünün günlük durumunu satış siparişi olarak netleştirerek sistemde aktif hale getirir.

6. İ̧lem planlama departmanı; master planlama modülünden planlı siparişler sekmesiyle satış siparişini üretime aktararak, üretim hareketlerine başlanılır.

7. İşlem planlama departmanı, master planlama çizelgeleme modülüyle mamul depodaki ürünleri süzerek satış siparişlerini planlı satış sipariş ekranına aktarır. Bu aşamada mamul depoda eksik görülen ürünlere öncelik verilir.

8. İşlem planlama departmanı planlı satış sipariş ekranı açarak sipariş durumunu üretim emri moduna çevirir.

9. İşlem planlama departmanı tarafından üretim emri açabilmesi için master plan oluşturulur. Siparişi kesinleştirerek üretim emri açılmış olur. 
10. İşlem üretim departmanı üretim modülünden açılan üretim emrinin ayrıntılarını inceler. Üretim emrindeki mamul ürünlerin ayrıntılarını inceler. Bu aşamada üretim hareketlerine başlanılmış olur. Üretim departmanı üretimi tamamlanan ürünleri bir üst ambara teslim eder. Ürün son olarak mamul depoya ulaşır.

11. İşlem üretim departmanı, stok yönetimi modülünden madde ayrıntıları sekmesi ile mamul stok ayrıntıları inceler.

12. İşlem mamul stok kontrolü yapıldıktan sonra master planlama modülünden maliyet simülasyondan satış sipariş numarasıyla süzerek ihtiyaç duyulan hammaddelerin maliyet analizi ve ihtiyaç planlaması yapılır.

13. İşlem hesaplanan maliyet analizine göre master plan hazırlanır ve manuel olarak planlama talep ekranında, talepler satın almaya iletilir.

14. İşlem açılan planlı satın alma siparişi, satın alma sipariş listesinden seçilir. İşlevlerden planlı sipariş durumunu değiştirilir. Planlanan satın alma siparişinin durumu onaylandı olarak sonlandırılır.

15. İşlem satın alma departmanı tarafından borç hesapları modülünden açık satın alma sipariş satırları incelenir.

16. İşlem satın almaya düşen tüm siparişler filtrelenerek incelenir. Bu filtreleme yapılarak eldeki malzemelerin stok durumu takip edilir.

17. İ̧lem eldeki malzemenin stok kontrolü, stok yönetimi modülünün eldekiler sekmesi sorgulanarak yapılır.

18. İşlem herhangi bir malzemenin stok kontrolünün yapılması.

19. İşlem satış siparişinin; stok durum kontrolü, üretim - paketleme ve üretim eksikleri modülünden süzülerek elde edilir. Burada satış sipariş kodu ve kodları tekil / çoğul eklenerek toplam stok durumu sorgulanır.

20. İşlem mamul depodan müşteriye teslim edilen ürünlere; muhasebe departmanı tarafından fatura kesilir. Muhasebe departmanı alacak hesapları modülünden satış siparişi ayrıntıları sekmesini açar.

21. İ̧lem muhasebe departmanı açılan ekranda, fatura kesilmesi satış siparişi kodunu süzerek fatura kesme hareketlerine başlar. Bu aşamada satış sipariş kodu girilerek elde edilen siparişin durumu teslim edildi olarak gözükmesi önemlidir. Fatura kesilmesi istenilen satış siparişine, sorgulamalar sekmesinden sevk irsaliyesi kesilir.

22. İ̧̧lem sevk irsaliyesi kesilmiş olan satış siparişine fatura kesmek için açılan ekrandaki; miktar, birim fiyat ve KDV oranı belirtilir. Daha sonra deftere nakil sekmesinden fatura kesmeye başlanır.

23. İşlem fatura kesme ekranında; fatura seri no ve fatura tarihi belirtilir. Bu aşamada istenilirse faturaya sipariş notu belirtilir.

24. İşlem muhasebe departmanı kesilen faturayı; sorgulamalar sekmesinden satış sipariş kodunu süzerek elde eder. Elde edilen kesilmiş faturanın raporu alınarak işlemi bitirir.

\section{SONUÇ VE TARTIŞMA}

Gelişen üretim teknolojisi, iletişim ağı ve ulaşım hızı nedeniyle küresel bir pazar oluşmuştur. Rekabet de küreselleşmiştir. Tüketiciler bilinçlenmiş, tüketiciyi koruyan yasalar ve kurumlar oluşmuştur. İşletmelerin var olan değişime ayak uydurmaları ve ileride yaşanabilecek değişime de hazır olmaları gerekmektedir. İşletme sistemlerinin işleyişinde, üretim planlaması ve kontrolü için birçok teknik geliştirilmiş ve uygulanmıştır. Hangi tekniğin hangi problemin çözümünde etkili olacağı yönünde işletmeler karar verirken, sorunlarını planlı bir biçimde ele almalı ve neden-sonuç ilişkilerini ortaya koymalıdır. Amaçlara en uygun tekniğin, en ekonomik, en kısa zamanda çözüme götüren ve olanaklı sonuçlar içinde en optimal sonucu veren bir teknik olması gerekir. Üretimin en etkili şekilde gerçekleştirilip, siparişlerin karşılanması ve üretim faaliyetlerinin kesintiye uğramaması için tedarikçiler ve tüketiciler arasında dengenin kurulabilmesi ile verimliliğin artmasını sağlamak, optimal düzeyde stok bulundurmak ve stoklara yapılan maliyeti en aza indirmek için işletme kontrolüne ve stok kontrolü yönetim sistemine gereksinim vardır.

\section{KAYNAKLAR}

Anonim 1, (2016) http://teknodergi.org/axapta-nedir-microsoft-dynamics-ax (Erişim tarihi: 14.04.2016)

Anonim 2, (2016) https://www.microsoft.com/tr-tr/dynamics/erp.aspx (Erişim tarihi: 14.04.2016)

Anonim 3, (2016) http://tr.wikipedia.org/wiki/Microsoft_Dynamics_AX, (Erişim tarihi: 05.03.2016) 
Bayar, B. (2004) Malzeme Ihtiyaç Planlaması ve Stok Yönetiminde Bir Işletme Uygulaması, M.Ü. Ekonometri ABD, İstanbul.

Bilgin, D. (2013) Kobi'lerde Modern Stok Yönetim Modellerinin Uygulanabilirliği: Karaman Ilinde Bir Uygulama, (Yüksek Lisans Tezi),Karamanoğlu Mehmetbey Üniversitesi Sosyal Bilimler Enstitüsü, Karaman.

Çolak, H. (2008) Stok Kontrolü ve Ekonomik Sipariş Miktarı Modellerinde Yeni Açılımlar: Ödemelerde Gecikmeye İin Verilmesi Durumu ve Bir Model Önerisi, (Doktora Tezi),Süleyman Demirel Üniversitesi Sosyal Bilimler Enstitüsü İ̧̧letme Anabilim Dalı, Isparta.

Erk, E. (2009) Talep Yönetimi Yolu ile Stok Kontrolü Üzerine Bir Model Önerisi ve Ticari Bir İşletmede Uygulama, (Doktora Tezi), Marmara Üniversitesi Sosyal Bilimler Enstitüsü Işletme Anabilim Dalı, İstanbul.

Güneçıkan, Ö. (2008) Kapasite Planlaması ve Optimum Stok Kontrolü Yönetimi, (Yüksek Lisans Projesi), Kahramanmaraş Sütçü Imam Üniversitesi Sosyal Bilimler Enstitüsü Işletme Anabilim Dalı, Kahramanmaraş.

Kaya, A. (2006) işletmelerde Stok Kontrolü ve Raf Yükü Maliyetinin Bir Sanayi işletmesinde Incelenmesi, (Yüksek Lisans Tezi), Dumlupınar Üniversitesi Iktisadi ve Idari Bilimler Fakültesi Işletme Anabilim Dalı, Kütahya.

Korkmaz, Ö. (2001) Üretim Kaynakları Planlaması ve Işletmelerdeki Uygulamaları, YTü Fen Bilimleri (Yayınlanmamış Yüksek Lisan Tezi), istanbul.

Öztürk, A. (2005) Yöneylem Araștırması, Ekin Kitabevi, Bursa.

Yeşiltaş, Ü. (2007) Stok Kontrolü ve Bilgisayar Donanım Sektöründe Bir Uygulama, (Yüksek Lisans Tezi), İstanbul Üniversitesi Sosyal Bilimler Enstitüsü İ̧letme Anabilim Dalı, i̇stanbul.

Yılancı, M., (2003) iç Denetim- Türkiye'nin 500 Büyük Sanayi Iş̧letmesi Üzerine Bir Araştırma, T.C. Osmangazi Ün. Yayınları, No:086, Eskişehir. 